\title{
Autocuidado: uma estratégia para a qualidade de vida da pessoa com estomia'
}

\author{
Marina Soares Mota² \\ Giovana Calcagno Gomes³ \\ Camila Daiane Silva ${ }^{4}$ \\ Vera Lúcia de Oliveira Gomes 5 \\ Marlene Teda Pelzer ${ }^{6}$ \\ Edaiane Joana Lima Barros
}

doi:10.11144/Javeriana.ie18-1.aeqv

Cómo citar: Mota M, Gomes G, Silva CD, Gomes VL, Pelzer M, Barros E. Autocuidado: uma estratégia para a qualidade de vida da pessoa com estomia. Investig Enferm. Imagen Desarr. 2016;18(1): 63-78. http://dx.doi.org/10.11144/Javeriana.ie18-1.aeqv

1. Artigo original de pesquisa. Recebido: 4 de março de 2015. Aceito: 10 de agosto de 2015 .

2. Doutoranda do Programa de Pós-Graduação em Enfermagem da Universidade Federal do Rio Grande, Brasil. Enfermeira da Secretaria de Saúde do Município de Pelotas. Membro do grupos de Estudos e Pesquisas sobre Enfermagem, Gênero e Sociedade (GEPEGS). Correio eletrônico: msm.mari.gro@gmail.com

3. Doutora em Enfermagem. Professora da Escola de Enfermagem, Universidade Federal do Rio Grande, Rio Grande, Brasil. Líder do GEPESCA. Orientadora do estudo. Correio eletrônico: acgomes@mikrus.com.br

4. Doutoranda do Programa de Pós-Graduação em Enfermagem da Universidade Federal do Rio Grande. Membro do Grupo de Estudos e Pesquisas sobre Enfermagem, Gênero e Sociedade (GEPEGS). Correio eletrônico: camilad.silva@yahoo.com.br

5. Doutora em Enfermagem. Professora da Escola de Enfermagem, Universidade Federal do Rio Grande, Rio Grande, RS, Brasil. Líder do Grupo de Estudos e Pesquisas sobre Enfermagem, Gênero e Sociedade (GEPEGS). Correio eletrônico: vlogomes@terra.com.br

6. Doutora em Enfermagem. Professora da Escola de Enfermagem, Universidade Federal do Rio Grande, Rio Grande, RS, Brasil. Líder do Grupo de Estudos e Pesquisa em Gerontogeriatria, Enfermagem/Saúde e Educação (GEPGERON). Correio eletrônico: pmarleneteda@ yahoo.com.br

7. Doutora em Enfermagem. Enfermeira responsável pelo Setor de Educação Permanente do Hospital Universitário Dr. Miguel Riet Correa Jr., Universidade Federal do Rio Grande, Rio Grande, RS, Brasil. Membro do Grupo de Estudos e Pesquisa em Gerontogeriatria, Enfermagem/Saúde e Educação (GEPGERON). Correio eletrônico: edaiane_barros@yahoo.com.br 


\section{Resumo}

A cirurgia de construção de uma estomia pode modificar o viver de seu portador, podendo reduzir a qualidade de vida deste. Objetivo: conhecer como o autocuidado con tribui para a qualidade de vida da pessoa com estomia. Método: a presente pesquisa, descritiva com abordagem qualitativa. Participaram doze pessoas com estomia ca dastradas no Serviço de Estomaterapia de um Hospital Universitário no extremo sul do Brasil. Os dados foram colhidos por meio de entrevistas, realizadas entre os meses de julho de 2011 a julho de 2012, analisadas pela técnica de Análise Temática. Resultados: a análise dos dados gerou três categorias: Enfermagem promovendo o autocuidado; Mobilizando forças para o autocuidado; e Qualidade de vida a partir do autocuidado. Conclusão: os dados mostraram que o autocuidado apresenta-se como propulsor da qualidade de vida de pessoas com estomias, possibilitando que sejam autônomos, ativos e participativos na sociedade.

Palavras chave: estomas cirúrgicos; autocuidado; qualidade de vida; cuidados de enfermagem

\section{Self-care: A Strategy for the Quality of Life of People with Stomata}

\section{Abstract}

A surgery to create a stoma changes the life of the patient and may reduce his quality of life. Thus the purpose of this descriptive research with a qualitative focus was to know how self-care contributes to promote the quality of life in patients with stomata. Twelve patients with stomata, registered in the Stoma Therapy Service of a university hospital in South Brazil, took part of the study. Data was collected through individual interviews carried out between July 2011 and July 2012, analyzed by means of the thematic analysis technique. The data analysis generated three categories: nursing promoting self-care, moving forces for self-control, and quality of life from self-control. Data shows that self-care is the driving force behind quality of life in patients with stomata, which allows them to be autonomous, active, and participative in society.

Keywords: surgical stomata; self-care; quality of life; nursing attention

\section{Autocuidado: una estrategia para la calidad de vida de la persona con estomas}

\section{Resumen}

La cirugía de construcción de un estoma cambia el vivir de su portador y puede reducir la calidad de su vida. Método: investigación descriptiva con enfoque cualitativo. Objetivo: conocer cómo el autocuidado contribuye a la promoción dela calidad de vida en pacientes con estomas. Participaron doce pacientes con estoma registrados en el Servicio de Estomaterapia de un hospital universitario en el sur de Brasil. Los datos fueron recolectados a través de entrevistas individuales llevadas a cabo entre julio de 2011 y julio de 2012, analizados mediante la técnica de análisis temático. Resultados: análisis de los datos generó tres categorias: enfermería que promueve el autocuidado, movilización de fuerzas para el autocontrol y calidad de vida a partir del autocontrol. Conclusion: los datos muestran que el autocuidado se presenta como motor de la calidad de vida en pacientes con estomas, lo que les permite ser autónomos, activos y participativos en la sociedad.

Palabras clave: estomas quirúrgicos; autocuidado; calidad de vida; atención de enfermería 


\section{Introdução}

A qualidade de vida refere-se à percepção que o indivíduo possui acerca de sua posição na vida, mediante o seu contexto cultural e sistema de valores e em relação aos seus objetivos, expectativas, padrões e preocupações. Envolve a avaliação dos impactos físicos, psicossociais e espirituais nos indivíduos, e a repercussão deles em relação à satisfação com a vida, bem-estar e integridade. Nesse sentido, saúde e doença têm papel relevante nesse contexto $(1,2)$.

Assim, um evento que leve à necessidade de uma cirurgia e da realização de um estoma pode trazer problemas de ordem física, psicológica esocial,podendo comprometer a qualidade de vida da pessoa (3). A estomização é um procedimento cirúrgico que exterioriza parte de um órgão oco, como o intestino ou bexiga, criando um orifício chamado estoma (4). Mesmo contribuindo para a continuidade da vida, o estoma altera a anatomia e a fisiologia,podendo comprometer o processo de viver, modificar o estilo de vida, o conceito de si e do outro, bem como a imagem corporal da pessoa que o possui.

A condição de pessoa com estomia pode gerar insatisfação com o corpo, baixa autoestima, sentimentos de autoexclusão, depressão e perda do desejo de retornar às atividades valorizadas e prazerosas. O processo de aceitação da nova condição de vida fica prejudicado, tornando-se uma fonte de sofrimento e vergonha, reduzindo as oportunidades de retorno à vida social e de (re)construção da autonomia e qualidade de vida destas pessoas (5-7).

A partir da cirurgia de estomização, a pessoa pode ter sua qualidade de vida reduzida devido a inquietações decorrentes da presença da bolsa coletora de fezes e/ou urina aderida ao abdômen, da presença de cicatrizes, do aspecto do estoma, da intolerância a certos alimentos, inapetência, problemas com a integridade da pele periestomal, constrangimentos devido à exalação de odores fétidos e ruídos desagradáveis, alterações na atividade sexual, dificuldade de retorno ao trabalho e medo da rejeição social $(7,8)$.

Para a melhoria do seu processo de viver a pessoa precisa compreender sua atual condição, visualizando as possibilidades de existir bem, mesmo necessitando da estomia. Como parte do processo de aceitação, é importante saber cuidar-se, além de preparar-se para enfrentar situações adversas. A insegurança e o constrangimento com a possibilidade de vazamento da bolsa coletora em lugares públicos fazem com que, muitas vezes, omitam a condição de pessoa com estomia ou evitem a convivência social (7). Nesse sentido, o desenvolvimento de novas habilidades e conhecimentos que propiciem o autocuidado contribui para o retorno às atividades diárias de forma segura, permitindo a interação social e um viver autônomo.

O autocuidado é definido "como um conjunto de condutas positivas que levam uma pessoa a tomar decisões e a praticar atividades facilitadoras da manutenção da estabilidade clínica e do enfrentamento da doença" (8). Corresponde às atitudes e aos cuidados realizados pelo paciente e familiares em benefício da sua saúde, na prevenção de doenças e no tratamento dos 
sintomas, sem supervisão formal de um profissional da saúde (9). Entretanto, os cuidados executados são, diversas vezes, aprendidos com os profissionais de saúde e adaptados pela pessoa conforme a realidade que essa vivencia.

Ao promover o autocuidado junto às pessoas com problemas crônicos de saúde, deve-se dar o suporte para o desenvolvimento de suas habilidades ou potencialidades, a fim de corresponsabilizá-las por sua saúde e ajudá-las a conviver melhor com a enfermidade, problematizar hábitos prejudiciais, manter hábitos saudáveis e estimular a autoconfiança, seja qual for a gravidade da doença (10).

Ressalta-se que, no âmbito domiciliar, muitas vezes, é a família que auxilia a pessoa com estomia nos primeiros passos rumo à independência. No entanto, espera-se que, após o período de adaptação, esta reassuma o cuidado de si e reconstrua sua autonomia de acordo com sua capacidade para a realização do autocuidado. As orientações, especialmente no pós-operatório recente, devem ser compartilhadas com a família. O sentimento de pertença e aceitação da família e amigos é relevante no processo de reabilitação e adaptação da pessoa com estomia, auxiliando na minimização ou maximização das consequências oriundas da estomia (9) e na reconstrução de sua autonomia, facilitando sua (re)inserção na sociedade. Dessa forma, a questão norteadora deste estudo foi: Como o autocuidado contribui para a qualidade de vida da pessoa com estomia?

Para isso, é imprescindivel que os profissionais da saúde, principalmente enfermeiros, realizem o acolhimento da pessoa com estomia e seu familiar cuidador, estabelecendo um processo dialógico para desvelar, de forma individualizada, suas necessidades (11).

\section{Objetivo}

Frente ao exposto, realizou-se esta pesquisa com o objetivo de conhecer como o autocuidado contribui para a qualidade de vida da pessoa com estomia.

\section{Método}

Estudo do tipo descritivo com abordagem qualitativa, desenvolvido no Serviço de Estomaterapia de um hospital universitário do sul do Brasil, entre os meses de julho de 2011 e julho de 2012. Este serviço funciona há vinte e quatro anos e atende cerca de 209 pessoas com estomias e seus familiares, realizando atividades de ensino, pesquisa e extensão.

Participaram do estudo 12 pessoas com estomias que atenderam aos critérios de inclusão: estar cadastrado e ativo no serviço, possuir a estomia há mais de um ano, apresentar bom estado de saúde, estando lúcido, orientado e comunicativo no momento da coleta de dados. Os que aceitaram participar assinaram o Termo de Consentimento Livre e Esclarecido.

Esses possuíam idades entre 49 e 92 anos, sendo nove homens e três mulheres. Sete eram aposentados, quatro, desempregados e um atuava realizando serviços gerais. Dois dos desempregados recebiam benefícios do governo. Quatro participantes perderam seus empregos após o adoecimento que desencadeou a cirurgia. 
Quanto ao tipo de estoma, seis eram colostomizados, quatro, ileostomizados e dois, urostomizados. O tempo de estomização variou entre dois meses a 19 anos. A principal causa da estomização foi o adenocarcinoma de reto (cinco), seguido pelo câncer de bexiga (dois) e da retocolite ulcerativa (dois), após, volvo intestinal, Síndrome de Fournier (um) e ruptura acidental do intestino (um). Dez pessoas possuíam estomias definitivas e apenas duas, temporárias.

Coletaram-se os dados por meio de uma entrevista semiestruturada na qual os participantes foram caracterizados e questionados sobre seu viver com a estomia, suas ações e experiências de autocuidado. As entrevistas, previamente agendadas, se realizaram no consultório do Serviço de Estomaterapia do hospital universitário, gravadas, transcritas e analisadas.

Os dados foram submetidos à análise temática proposta por Minayo (12). Tal método se operacionalizou em três etapas: a pré-análise, na qual houve o agrupamento das falas e elaboração das unidades de registro; a exploração do material, na qual os dados foram codificados, agrupados por semelhanças e diferenças e organizados em categorias; e o tratamento dos resultados obtidos e interpretação, em que as falas mais significativas foram selecionadas para ilustrar a análise e realizada a busca de autores para dar suporte à discussão dos dados (12). Surgiram como categorias temáticas: a promoção do autocuidado como prática educativa, a mobilização de forças para se autocuidar e a qualidade de vida a partir do autocuidado.

Respeitou-se a Resolução 466/12 no que tange aos aspectos éticos para pesquisa com seres humanos (13). Identificaram-se as falas pela letra $\mathrm{P}$, referindo-se a pessoa, seguida do número sequencial da entrevista. O projeto foi aprovado pelo Comitê de Ética em Pesquisa Área da Saúde (CEPAS) da Universidade Federal do Rio Grande, sob Parecer 148/2011.

\section{Resultados}

A seguir serão apresentadas as categorias geradas a partir da análise temática dos dados.

\section{A promoção do autocuidado como prática educativa}

A cirurgia de estomização determina o início da dependência da bolsa coletora de efluentes. Esta, geralmente, apresenta-se como algo novo e estranho para a pessoa com estomia. Fazem-se necessárias ações orientadoras que a preparem para o enfrentamento das novas demandas de cuidado e que a auxiliem a, progressivamente, adquirir habilidades para se autocuidar, se tornando, conforme a possibilidade, autônoma e independente. É neste momento que se observa o papel dos profissionais, em especial do enfermeiro, na realização da educação em saúde, objetivando o ensino do autocuidado:

"Tinha umas feridinhas, mas vinha aqui e consultava com a Enfermeira, fazia o que me explicavam e resolvia" (P6). 
“Não queria cuidar. Nos primeiros meses eu não queria mexer, até pela cicatrização que não estava bem ainda. Mas depois fui no Serviço de Estomaterapia e consultei com a Enfermeira, aprendi bem e comecei a fazer sozinha" (P3).

O autocuidado pode surgir após a compreensão do que significa a estomia e como a pessoa se vê estomizada. Alguns só conseguem realizar o autocuidado determinado tempo após a alta hospitalar. Durante o período de internação é possível aprender os cuidados que necessitarão realizar no domicílio a partir das orientações recebidas pelo Enfermeiro.

"As enfermeiras do hospital me explicaram direitinho e depois comecei a fazer sozinho. Não me atrapalhei em nada, pois me explicaram bem, fizeram algumas vezes e disseram que a partir daquele momento eu tinha que fazer sozinho" (P7).

O enfermeiro, ao realizar as orientações, valendo-se da educação em saúde, utiliza seu conhecimento científico e sua proximidade com a pessoa a ser cuidada, fomenta a realização do autocuidado a partir das individualidades do cliente, estabelecendo conjuntamente estratégias que promovam a independência e a qualidade de vida.

\section{A mobilização de forças para se autocuidar}

Diversas são as formas motivadoras do autocuidado. Observa-se em especial que a pessoa com estomia, mesmo incentivada pelos profissionais, precisa decidir por desenvolver habilidades e competências gerando a vontade de readquirir a autonomia para o cuidado, visualizando que essa atitude mudará sua vida.

"As Enfermeiras vinham, davam atenção e me explicavam. Mas quando eu decidi que faria foi que consegui fazer direito. Precisava tomar a decisão. Só aí que eu aprendi de verdade. Só aí minha vida melhorou mesmo. Parei de depender dos outros" (P12).

"Faço tudo sozinho. Isso partiu de mim mesmo. Para não transferir o problema para ninguém. Para não depender de ninguém" (P10).

Nem sempre a decisão surge de forças internas próprias da pessoa com estomia. Múltiplos são os aspectos que a motivam a decidir pelo autocuidado, entre eles está a falta do familiar cuidador. Constatou-se que a realização do autocuidado pode ser influenciada pela capacidade de cada pessoa com estomia realizá-lo ou não e da disponibilidade ou não de alguém para, no momento da necessidade, fazer por ela. 
"Foi na necessidade. Minha mulher viajou e tive que fazer. Percebi que deu certo e passei a fazer. Acho que já sabia de ver ela fazer e de ajudar, mas ainda não havia trocado a bolsa sozinho" (P5).

A família, muitas vezes, na busca de apoiar, se excede nos cuidados, estimulando uma codependência. O auxílio da família no enfrentamento da doença e nos cuidados inicialmente é imprescindivel, entretanto, a pessoa com estomia não deve se tornar dependente do cuidado de terceiros, visto que, na falta do mesmo, pode ser submetida a constrangimentos, dificuldades, acarretando traumas e inseguranças, prejudicando a sua autonomia e qualidade de vida.

O cuidado profissional e familiar são essenciais logo após a cirurgia, mas devem ser, gradativamente, transferidos à pessoa com estomia à medida que ela se recupera e adquire segurança e capacidade para realizá-lo. O processo de autocuidado normalmente é alcançado quando a pessoa com estoma consegue desenvolver seu cuidado, incluindo o manuseio da bolsa coletora, a sua higiene, bem como, a estabilidade para o enfrentamento de situações adversas. Dessa forma, desenvolver habilidades e competências para o exercício do autocuidado pode auxiliá-la a retomar suas atividades de vida diária, contribuindo para o viver pleno com qualidade.

"Minha irmã é enfermeira e começou a me ajudar. Ela pedia para segurar aqui, ajudar ali. E um dia eu disse: Não, deixa eu ver se eu consigo. Porque eu ficava com medo de agarrar e fazer aquele furinho e ficar em cima do estoma. Ficava com medo, mas fiz tudo certinho e, agora, eu troco. Depois disso não dependi mais de ninguém" (P12).

O enfermeiro, em suas ações de educação em saúde, não visualiza apenas a pessoa com estomia, mas toda a sua rede de apoio aos cuidados, de que ela necessita. Tanto a pessoa quanto o familiar precisam preparar-se para cuidar e compreenderem até que ponto o familiar deve ajudar sem criar a dependência, nem desamparar. Assim, o enfermeiro precisa estabelecer um diálogo claro onde cada pessoa exerça uma função determinada com o objetivo do alcance do autocuidado.

A determinação e o desejo da pessoa com estomia em realizar seu autocuidado são importantes, visto que cada procedimento efetivado com êxito estimula e motiva o desenvolvimento de forças no sentido da conquista da autonomia e do autocuidado, reduzindo, assim, a dependência do outro ao mínimo necessário.

"A higiene faço sozinho. Depois eu peço para o meu filho colocar a bolsa" (P4).

"A única coisa que não consigo é cortar a bolsa direitinho. Mas, colocar, eu já boto" (P5). 
Pensar-se como pessoa com estomia pode ser uma reflexão difícil, tendo em vista o incerto e o desconhecido que espera o novo estomizado. Entretanto, o convívio com outras pessoas que possuem uma estomia permite a troca de experiências e de informações em que ela visualiza a concretude do viver com uma estomia e suas possibilidades. Esse contato a auxilia a aprender e reforça a necessidade do autocuidado.

"Aconselho quem puder fazer a irrigação. Os colegas estomizados e o Serviço de Estomia me deram as orientações, e depois fui lá, fiz e, até hoje, não passo trabalho nenhum. Se pudesse recomendar a todo mundo no grupo, se tivessem a força de fazer isso aí, sentiriam outros. Para mim foi muito bom" (P10).

Observa-se que a pessoa com estomia, ao obter êxito em suas experiências, sente a necessidade de repassar isso para os demais integrantes do grupo. Fato que promove a união do grupo, incentiva os participantes a novas vivências, além de exemplificar as possibilidades de viver com a estomia com qualidade de vida. No caso acima apresentado, a autoirrigação mostrou-se como uma estratégia libertadora, viabilizando um controle sobre suas eliminações intestinais, o que refletiu diretamente na qualidade de vida.

\section{O processo de viver a partir do autocuidado}

O isolamento da sociedade é comum em algumas pessoas com estomia, em especial quando esta é recente. Isso pode surgir por medos, inseguranças e constrangimentos por temerem que o estoma ou a bolsa coletora fiquem evidentes ou ocorra algum evento adverso, como o vazamento da mesma em locais públicos.

Verificou-se que, com o passar do tempo, e com a aquisição de conhecimentos e a (re)adaptação ao cotidiano como pessoa com estomia, esta pode, a partir do autocuidado, se sentir capaz de voltar a frequentar lugares que evitava por medo de constrangimentos.

"Eu evitava sair na rua, pois se vazasse seria o maior constrangimento. Depois comecei a me acostumar com a bolsa, a trocar sozinho e comecei a sair mais. Então esse tipo de atividade ficou normal. Depois que comecei a me cuidar sozinho tudo melhorou" (P2).

A cirurgia de estomização transforma o corpo da pessoa, necessitando que ela aprenda a conviver com as mudanças corporais após a cirurgia (cicatriz cirúrgica, presença de um estoma abdominal, nova forma de evacuar ou urinar), aprendendo uma nova forma de viver como um ser com estomia. Tal processo é individual e pode ser lento, entretanto, ao consolidar-se como pessoa com estomia, estabelece uma relação positiva com tecnologias e desenvolvendo habilidades de cuidados que adquirem um 
significado importante no seu cotidiano, facilitando sua (re)inserção social com mais confiança e segurança, visto que se permite continuar vivendo com qualidade de vida.

"Depois que passei a fazer a irrigação, melhorou 1000\% socialmente. Estou mais seguro e confiante" (P10).

"Com o tempo aceitei meu corpo, o estoma e a bolsa coletora. Hoje me sinto forte para me cuidar" (P1).

A consolidação do cuidado, muitas vezes, surge a partir da repetição das técnicas de cuidado com a estomia. As novas tecnologias de cuidado são inseridas, normalmente, pela necessidade de independência e/ou conforto, sendo promotoras da autonomia e da autoestima, repercutindo positivamente no processo de viver saudável.

"Nunca usei o tampão [oclusor de estoma], mas quero tentar. Não pela roupa, mais para não ter que limpar toda hora na viagem" (P6).

As experiências e situações vivenciadas pela pessoa produzem um crescimento e amadurecimento, modificando o enfrentamento do viver com a estomia. A visão de si e da bolsa coletora aderida ao abdômen podem modificar-se, passando a reconhecê-la como importante para seu autocuidado, sendo capaz de enfrentar com tranquilidade essa nova forma de viver, que pode lhe proporcionar uma agradável e prazerosa convivência social.

"Fui me adaptando cada vez mais. Porque já é uma parte do meu corpo. Virou parte do meu corpo. Depois que passei a fazer eu não tive mais problema nenhum" (P8).

"Eu fui adaptando. Uma coisinha aqui, outra ali, e para mim se tornou normal. Eu só lembro-me dela [a bolsa] quando eu falo. De resto é normal” (P4).

O tempo se mostra um aliado para a normalização e a aceitação do viver com uma estomia, chegando a reconhecê-la como parte de si, desenvolvendo novos conceitos quanto à sua imagem e vida, possibilitando um viver ativo e com qualidade. Instigar a pessoa a adaptar-se de forma autônoma, pelo enfermeiro e família, também possibilita que retorne, de maneira aproximada, ou melhor, à qualidade de vida conhecida antes da cirurgia.

\section{Discussão}

Participaram do estudo 12 pessoas com estomias, com idades entre 49 e 92 anos, sendo nove homens e três mulheres. Sete eram aposentados, quatro, desempregados. Quanto ao tipo de estoma, seis eram colostomizados, quatro, ileostomizados e dois, urostomizados. O tempo de estomização variou entre dois meses e 19 anos. A principal causa da estomização foi o adenocarcinoma 
de reto (cinco), seguido pelo câncer de bexiga (dois). Estudo mostrou que a maioria das cirurgias eram colostomias (67\%), seguidas de ileostomia (21\%) e urostomia (11\%) (14).

Estudo semelhante evidenciou uma idade média de 53,5 anos entre os participantes que, em sua maioria, eram homens. Neste, grande parte foi forçada a mudar de emprego, alterar a dieta e o estilo de vestir (15). Percebese que, ao tornar-se uma pessoa com estomia, o indivíduo modifica hábitos e costumes, o que na maioria das vezes afeta sua qualidade de vida (15).

No mundo contemporâneo o câncer encontra-se entre os principais fatores de morbimortalidade. No Brasil, o câncer do sistema gastrointestinal e do sistema urinário têm uma incidência relevante, sendo os principais responsáveis pelas estomizações (16). O diagnóstico de câncer traz mudanças importantes no modo de viver, com alterações físicas e emocionais devido ao desconforto, dor, desfiguração, dependência e perda da autoestima, comprometendo a qualidade de vida (15).

A cirurgia de estomização pode causar diversas alterações no processo de viver desse indivíduo. Além da mutilação do corpo, este passa a depender de uma bolsa coletora para o depósito de seu efluente (17). O uso de materiais e equipamentos próprios para o cuidado do estoma e pele periestomal, como bolsas e seus adjuvantes, é, geralmente, algo novo e estranho à pessoa que se tornará ou tornou-se recentemente estomizada, suscitando a necessidade de orientações que a preparem para lidar com as novas demandas de cuidado com o estoma e, progressivamente, a aquisição de habilidades para o autocuidado, que lhe proporcionarão autonomia e independência.

O enfermeiro ocupa uma posição de destaque frente à assistência às pessoas com estomias, seja por seu conhecimento científico, por seu envolvimento no momento do diagnóstico, do pré e pós-cirúrgico e no acompanhamento ambulatorial ou, ainda, pelo desenvolvimento de ações de educação em saúde e promoção do autocuidado (18). Um estudo, acerca da qualidade de vida de pessoas com estomias, sugere que os enfermeiros criem em seu cotidiano de assistência espaços para a comunicação, contribuindo para que as pessoas com estomias sintam-se à vontade e aos poucos aceitem sua nova imagem corporal e prezem pela sua qualidade de vida (19).

A Enfermagem desempenha ações de orientação e educação em diversas dimensões da vida da pessoa com estomia, como física, emocional, social, econômica, familiar, sexual. Por acompanhar todas as etapas da estomização, o enfermeiro deve estabelecer vínculos com a pessoa e sua família, favorecendo intervenções de enfrentamento da situação, estimulando a busca por uma qualidade de vida satisfatória (19). Além de interagir com os demais profissionais que se envolvem na recuperação da pessoa, discutindo estratégias de cuidado que auxiliem a ela e à família no enfrentamento do cotidiano após a cirurgia de estomização.

É importante que enfermeiros e demais profissionais da área da saúde estejam preparados para prestar assistência adequada e de qualidade a essa população. Para tanto, é preciso que vivências nessa área sejam oportunizadas, sensibilizando os profissionais para a necessidade de cuidados e atenção durante o tratamento de indivíduos estomizados (20). 
O atendimento no Serviço de Estomaterapia é previsto por meio da Portaria SAS/MS n 400 de 16 de novembro de 2009, que estabelece a composição básica da equipe que deve atuar nesse Serviço; são duas classes: a classe I com enfermeiro, médico clínico e assistente social, ou classe II, com enfermeiro, médico generalista ou especialista na área cirúrgica, assistente social, nutricionista e psicólogo (4).

Independente da classe do serviço, o enfermeiro compõe a equipe que atende a pessoa com estomia, objetivando sua saúde por meio do autocuidado. Dentro do contexto da aquisição do autocuidado, o enfermeiro emerge como agente transformador da saúde ao atuar como educador de pessoas com estomias e suas famílias, utilizando tecnologias educativas que ajudam a facilitar a compreensão do conhecimento, tornando o processo de aprendizagem mais simples e exequível (21).

Assim, os Enfermeiros são elementos essenciais no processo de reabilitação das pessoas com estomias, pois se fazem presentes no início do diagnóstico, ao participar da decisão da realização da cirurgia de estomização ainda em ambiente ambulatorial ou hospitalar, no pré-operatório, na hospitalização, na alta e no pós-operatório tardio, seja nos Serviços de Estomaterapia, postos de saúde ou equipes de saúde da família. Nesse sentido, é primordial que, durante sua formação no Curso de Graduação em Enfermagem, lhes sejam transmitidos conhecimentos que os habilitem a atuar junto à pessoa com estomia e sua família. Além disso, a Estomaterapia apresenta-se como uma especialidade que visa à formação de enfermeiros em nível de pós-graduação (22).

Muitos, após a cirurgia, desenvolvem sentimentos como tristeza e depressão, optando pelo isolamento social (15). Esses e outros fatores precisam ser trabalhados pela equipe de saúde, com vistas a facilitar a recuperação da pessoa com estomia e subsidiá-la para que exerça seu cuidado de forma plena. Para tanto, é necessário incentivá-la a tornar-se independente, pois a autonomia é um dos fatores que facilitam a obtenção de qualidade de vida e (re)inserção social. Estudo mostrou uma clara relação entre autonomia e qualidade de vida (23). É necessário que a pessoa com estomia se emancipe e consiga viver sem ajuda. A apreensão de conhecimentos e a aquisição de habilidades manuais para o desenvolvimento do autocuidado são essenciais para o processo de retomada do cotidiano, na busca pela independência, evitando a restrição ao lar e o isolamento social (24).

Muitas vezes a pessoa acomoda-se com o auxílio de um familiar ou amigo, sendo mais fácil ser cuidado do que enfrentar a situação. Assim, o enfermeiro precisa acompanhar o cotidiano da pessoa com estomia e sua família, orientando sob as formas de cuidar sem exceder-se, permitindo que a pessoa reassuma a responsabilidade pelo seu próprio cuidado (21).

O enfermeiro desenvolve ações não somente com a pessoa com estomia, mas com seus familiares/cuidadores. Verifica-se que ele se preocupa com o tempo dispensado pela família para auxiliá-la em seus cuidados, pois, frente à estomização, há a necessidade do apoio e do estímulo (25). Dessa forma, o cuidado exercido pela enfermagem deve focar também a família, visto que ela, muitas vezes, precisa ser habilitada para cuidar da pessoa e se autocuidar. 
A atuação do enfermeiro, como forma de estimular a autonomia, vale-se da educação em saúde como ferramenta para estimular o diálogo, a reflexão, o questionamento e a ação compartilhada. Tanto para a pessoa quanto para a família, as ações educativas, tornam-se essenciais para a compreensão das modificações e das possibilidades de melhoria na qualidade de vida dessas pessoas (16). Demonstra-se Configura-se como um desafio à família, não somente dar apoio físico e emocional à pessoa, mas trabalhar com ela, reforçando sua corresponsabilidade e a importância da autonomia, instrumentalizando-a para que ela seja capaz de agir sozinha. A confiança, a autonomia, é são algo (re)conquistado ao longo do tempo, envolvendo momentos bons e ruins que vão se ajustando lentamente até a realização do efetivo autocuidado (21).

A vontade e a disponibilidade da pessoa para a realização dos cuidados com o estoma são importantes, pois cada procedimento concretizado satisfatoriamente apresenta-se como um estímulo à conquista da autonomia e do autocuidado pleno, pois, assim, a dependência do outro fica reduzida ao mínimo necessário. O convívio com outras pessoas com estomias também se mostra um incentivo, pois a troca de experiências e de informações pode apoiar no enfrentamento do viver com estomia, demonstrando que é possível conviver e ter qualidade de vida.

Nota-se que a pessoa com estomia sente necessidade de repassar suas experiências positivas, objetivando auxiliar no enfrentamento do cotidiano de outras pessoas. A autoirrigação, no caso deste estudo, mostra-se como exemplo de tecnologia importante na reabilitação da pessoa com estomia, tipo colostomia, que possibilita o controle intestinal mais efetivo, refletindo diretamente na qualidade de vida (26), permitindo que esta tenha controle sobre suas eliminações e, consequentemente, sobre sua vida, sendo incentivada pelos que obtiveram êxito ao utilizar tal tecnologia.

Visualiza-se que cada pessoa, a partir de suas vivências e experiências com o cuidado do estoma, pode apresentar-se como um potencializador de outras pessoas na mesma situação de vida, encorajando-as para a decisão do autocuidado. Com o intuito de promover essa troca de experiências e apoio mútuo, que resulta no autocuidado, o papel do grupo de apoio se sobressai, evidenciando a eficácia no enfrentamento da condição de estomizado, na busca por uma melhor qualidade de vida (15). O grupo mostra-se como um exemplo valioso de estratégia para a instrumentalização da pessoa no tocante às informações e técnicas vivenciadas para o cuidado.

O grupo também permite discutir questões de relações sociais, visto que o isolamento social é comumente observado nas pessoas com estomia, mesmo que transitória. Para elas, a sua nova condição gera medo e constrangimento, temem que o estoma ou a bolsa coletora fiquem evidentes ou que ocorra o vazamento em locais públicos (27). Assim, acredita-se que adquirir conhecimentos necessários para se autocuidar aumenta aumente as chances de enfrentar as adversidades, permitindo que esta (re)insira-se estas se (re)insiram de forma segura e plena na sociedade.

Ao tornar-se uma pessoa com estomia, precisam precisa aprender a conviver com o novo corpo, ou seja, adaptar-se a um novo modo de viver, e 
isso é um processo lento e individual, que depende de diversos fatores, como a assistência recebida e o seu próprio interesse desta (27). Nesse processo, na rotina diária, o contato da pessoa com a bolsa coletora e demais tecnologias específicas de cuidado adquirem adquire um significado importante no seu cotidiano, pois tais cuidados e tecnologias terão que ser incorporados no seu cotidiano, facilitando sua (re)inserção social com mais confiança e segurança.

Com a repetição das técnicas de cuidado com a estomia, as pessoas vão, gradativamente, adquirindo habilidades para o autocuidado, possibilitando uma maior independência em relação às outras pessoas (27). Assim, o aprendizado de novas tecnologias facilita o autocuidado e aumenta a qualidade do processo de viver da pessoa, pois são promotoras da autoestima e repercutem positivamente no processo de viver saudável.

A partir das experiências e situações vivenciadas, o indivíduo amadurece e cresce como pessoa. Um estudo com adolescentes com estomia afirma que adquirir conhecimentos, através de recursos diversos, como panfletos, notícias, Internet e pela interação com os profissionais da saúde, auxilia na manutenção da saúde, refletindo na qualidade de vida destes (17).

Com o tempo, o acesso à informação, a tecnologias, ao apoio recebido pelos profissionais e família, a pessoa passa a reconhecer a bolsa coletora como parte constituinte de seu corpo, sendo capaz de enfrentar com tranquilidade essa nova forma de viver, que pode lhe proporcionar uma agradável e prazerosa convivência social. A partir do reconhecimento da estomia como parte de si, é possivel auxiliar esses clientes a se (re)conhecerem, aceitarem a si e aos outros, serem sensiveis e descobrirem seus projetos de vida (17).

Os Enfermeiros fazem parte desse processo de adaptação e aceitação, pois, além de cuidadores, são educadores. Para tanto, precisam conhecer a realidade dos seus clientes, instigando-os a serem ativos, críticos, reflexivos e participativos (27). Dessa forma, o abandono da condição de passividade é de extrema importância para a pessoa com estomia, pois, assim, ela pode reconhecer sua importância no mundo, o que se reflete em seus sonhos, desejos e expectativas, melhorando seu processo de viver.

\section{Conclusões}

O estudo alcançou o objetivo de conhecer como o autocuidado contribui para a promoção da qualidade de vida de pessoas com estomias. Assim, a qualidade do processo de viver é possivel, a partir do autocuidado, e depende de diversos fatores, como o acesso à tecnologia de cuidado, ao atendimento especializado de enfermagem, ao auxílio da família e do grupo de apoio, mas, principalmente, à da mobilização de forças internas no sentido de se autocuidar.

Conclui-se que o autocuidado apresenta-se como estratégia do processo de viver, possibilitando às pessoas com estomia reconstruirem-se como seres autônomos, ativos e participativos na sociedade. Dessa forma, mostra-se de grande importância a realização de novos estudos, a fim de para identificar outros fatores que contribuem contribuam para a qualidade de vida desses clientes. 


\section{Financiamento}

Estudo realizado com auxílio da Fundação de Amparo à Pesquisa do Rio Grande do Sul- FAPERGS, através do Programa de Bolsas de Iniciação Científica-PROBIC, projeto O Portador de Estomia e sua (Re)Inserção Social.

\section{Conflito de interesses}

Os autores declaram que não haver conflitos de interesses.

\section{Referências}

1. Mattevi BS, Bredemeier J, Farm C, Fleck MP. Quality of care, quality of life, and attitudes toward disabilities: perspectives from a qualitative focus group study in Porto Alegre, Brazil. Rev Panam Salud Publica [Internet]. 2012 mar [citado abr 2015];31(3):188-96. Disponivel em: http://www.ncbi.nlm.nih.gov/pubmed/22569692.

2. Nicolussi AC, Sawada NO. Fatores que influenciam a qualidade de vida de pacientes com câncer de cólon e reto. Acta Paul Enferm [Internet]. 2010 [citado abril 2015];23(1): 125-30. Disponivel em: http://www.scielo.br/ scielo.php?script $=$ sci_arttext\&pid=S0103-21002010000100020\&lng=en.

3. Brasil, Ministério da Saúde. Portaria SAS/MS no 400 de 16 de novembro de 2009 [Internet]. Brasília, 2009 [Citado dez 2014]. Disponivel em: http://bvsms.saude.gov.br/bvs/saudelegis/sas/2009/ prt0400_16_11_2009.html.

4. Kimura CA, Kamara I, Fortes RC, Monteiro PC. Reflexões para os profissionais de saúde sobre a qualidade de vida de pacientes oncológicos estomizados. Com Ciências Saúde [Internet]. 2009 [citado dez 2014];20(4):333-40. Disponivel em: http://www.escs.edu.br/pesquisa/ revista/2009Vol20_4art7reflexoes.pdf

5. Souza PCM, Costa VRM, Maruyama SAT, Costa ALRC, Rodrigues AEC, Navarro JP. As repercussões de viver com uma colostomia temporária nos corpos: individual, social e político. Rev Eletr Enf [Internet]. 2011 [citado jan 2015];13(1):50-9. Disponivel em: http://www.fen.ufg. br/fen_revista/v13/n1/pdf/v13n1a06.pdf

6. Cassero PAS, Aguiar JE. Percepções emocionais influenciadas por uma ostomia. Rev Saúde e Pesquisa. 2009 [citado dez 2014];2(2):237. Disponivel em: http://periodicos.unicesumar.edu.br/index.php/ saudpesq/article/viewFile/1058/780.

7. The WHOQOL Group. The World Health Organization quality of life assessment (WHOQOL): Position paper from the World Health Organization. Soc Sci Méd. 1995 [citado mar 2015]; 1403-10. Disponível em: http://www.ncbi.nlm.nih.gov/pubmed/8560308

8. Riegel B, Moser DK, Anker SD, et al. American Heart Association Interdisciplinary Council on Quality of Care and Outcomes Research. State of the science: promoting self-care in persons with heart failure: a scientific statement from the American Heart Association. 2009 [citado fev 2015];120(12):1141-63. Disponível em: http://www.ncbi.nlm. 
nih.gov/pubmed/?term=American+Heart+Association+Interdisciplina ry+Council+on+Quality+of+Care+and+Outcomes+Research.+State+of.

9. Amorim MMA, Ramos N, Bento IC, Gazzinelli MF. Intervenção educativa na diabetes mellitus. Psicologia Saúde Doenças. 2013 [citado jan 2015];14(1):168-84. Disponivel em: http://www.scielo.oces.mctes.pt/ scielo.php?pid=S1645-00862013000100011\&script=sci_arttext\&tlng=pt.

10. Baquedano IR, Santos MA, Martins TA, Zanetti ML. Autocuidado de pessoas com diabetes mellitus atendidas em serviço de urgência no México. Rev Latino-Am Enfermagem. 2010 [citado mar 2015];18(6):[09 telas]. Disponivel em: http://www.scielo.mec.pt/pdf/psd/v14n1/ v14n1a11.pdf.

11. Brum CN, Sodré BS, Prevedello PV, Quinhones SWM. O processo de viver dos pacientes adultos com ostomias permanentes: uma revisão de literatura. R Pesq: Cuid Fundam [Internet]. 2010 [citado jan 2015];2(4):1253-63. Disponivel em: http://www.seer.unirio.br/index. php/cuidadofundamental/article/viewFile/660/pdf_83.

12. Minayo MC de S. Pesquisa social: teoria, método e criatividade. $29^{a}$ ed. Petrópolis (RJ): Vozes; 2010.

13. Brasil, Ministério da Saúde, Conselho Nacional de Saúde. Diretrizes e normas regulamentadoras sobre pesquisa envolvendo seres humanos. Resolução 466 de 2012. Brasília, DF: CNS; 2012 [citado mar 2014]. Disponivel em: http://conselho.saude.gov.br/resolucoes/2012/Reso466.

14. Anaraki F, Vafaie M, Behboo R, Maghsoodi N, Esmaeil pour S, Safaee A. Quality of life outcomes in patients living with stoma. Indian J Palliat Care [internet]. 2012 [citado mar 2015];18(3):176-80. Disponivel em: http://www.ncbi.nlm.nih.gov/pubmed/23439841.

15. Mansano-Schlosser TC, Ceolim MF. Qualidade de vida de pacientes com câncer no período de quimioterapia. [Internet]. 2012 set [citado abr 2015];21(3):600-7. Disponivel em: http://www.scielo.br/scielo. php?script $=$ sci_arttext\&pid=S0104-07072012000300015\&lng=en. http://dx.doi.org/10.1590/S0104-07072012000300015.

16. Cunha RR, Backes VMS, Heidemann ITSB. Desvelamento crítico da pessoa estomizada: em ação o programa de educação permanente em saúde. Acta Paul Enferm. 2012 [citado fev 2015];25(2):296-301. Disponivel em: http://www.scielo.br/scielo.php?script=sci_arttext\&pid =S0103-21002012000200022.

17. Mota MS, Gomes GC. Mudanças no processo de viver do paciente estomizado pós cirurgia. Rev Enferm UFPE [internet]. 2013 [citado fev 2015];7(12):7074-81. Disponivel em: file://C:/Users/Marina/ Downloads/3435-50885-1-PB\%20(7).pdf.

18. Moraes JT, Sousa LA, Carmo WJ. Análise do autocuidado das pessoas estomizadas em um município do centro oeste de Minas Gerais. R Enferm Cent O Min [internet]. 2012 [citado jan 2015];2(3):337-46. Disponivel em: http://www.seer.ufsj.edu.br/index.php/recom/article/ viewArticle/224. 
19. Sinha A, Goyal H, Singh S, Rana SP. Quality of life of ostomates with the selected factors in a selected hospital of Delhi with a view to develop guidelines for the health professionals. Indian J Palliat Care [internet]. 2009 [citado fev 2015];15(2):111-4. Disponivel em: http:// www.ncbi.nlm.nih.gov/pubmed/20668588

20. Barros EJL, Santos SSC, Gomes GC, Erdmann AL. Gerontotecnologia educativa voltada ao idoso estomizado à luz da complexidade. Rev Gaúcha Enferm [intenet]. 2012 [citado abr 2015];33(2):95-101. Disponível em: http://seer.ufrgs.br/index.php/RevistaGauchadeEnfermagem/ article/view/16325/19498.

21. Mauricio VC, Souza NVDO, Lisboa MTL. O enfermeiro na reabilitação da pessoa com Estoma. Esc Anna Nery [Internet]. 2013 [citado abr 2015];17( 3):416-22. Disponivel em: http://www.scielo.br/scielo.php?script=sci_arttext\&pid=S1414-81452013000300416\&lng=en.

22. Cobo CM. The influence of institutionalization on the perception of autonomy and quality of life in old people. Rev Esc Enferm USP. 2014 Dez [citado abr 2015];48(6):1013-9. Disponivel em: http://www.scielo. br/pdf/reeusp/v48n6/0080-6234-reeusp-48-06-1013.pdf.

23. Ardigo FS, Amante LN. Conhecimento do profissional acerca do cuidado de enfermagem à pessoa com estomia intestinal e família. Texto Contexto-Enferm [Internet]. 2013 [citado abr 2015];22(4):1064-71. Disponível em: http://www.scielo.br/scielo. php?script=sci_arttext\&pid=S0104-07072013000400024\&lng=en.

24. Nicholas DB, Swan SR, Gerstle TJ, Allan T,Griffiths AM. Struggles, strengths, and strategies: an ethnographic study exploring the experiences of adolescents living with an ostomy. Health Qual Life Outcomes. 2008 [Citado jan 2015];6(1):114. Disponivel em: http:// www.hqlo.com/content/6/1/114.

25. Cesaretti IUR, Santos VLCG, Vianna LAC. Qualidade de vida de pessoas colostomizadas com e sem uso de métodos de controle intestinal. Rev Bras Enferm. 2010 [Citado dez 2014]; 63(1): 16-21. Disponivel em: http://www. scielo.br/scielo.php?script=sci_arttext\&pid=S0034-71672010000100003.

26. Nascimento CMS, Trindade GLB, Luz MHBA, Fontes RS. The ostomy patient's living experience: a contribution to nursing care. Texto Contexto-Enferm. 2011 [citado jan 2015];20(3):557-64. Disponivel em: http://www.scielo.br/scielo.php?pid=S0104-07072011000300018\&script $=$ sci_arttext.

27. Martins PAE, Alvin NAT. Perspectiva educativa do cuidado em enfermagem sobre a manutenção da estomia de eliminação. Rev Bras Enferm [Interneet]. 2011 [citado fev 2015];64(2):322-7. Disponível em: http://www. scielo.br/scielo.php?script=sci_arttext\&pid=S0034-71672011000200016. 